\title{
Acil Serviste Kan Transfüzyonu Yapılan Hastaların Özellikleri
}

\section{Yeşim İŞLER ${ }^{1}$, Halil KAYA ${ }^{1}$, Şükrü İ̧LER ${ }^{2}$, Melih YÜKSEL $^{1}$}

1 Sağlık Bilimleri Üniversitesi, Bursa Yüksek İhtisas Eğitim ve Araştırma Hastanesi, Acil Tıp Kliniği, Bursa.

2 Sağlık Bilimleri Üniversitesi, Bursa Yüksek İhtisas Eğitim ve Araştırma Hastanesi, Plastik ve Rekonstrüktif Cerrahi Kliniği, Bursa

\section{ÖZET}

$\mathrm{Bu}$ çalışmanın amacı acil serviste kan ve kan ürünleri transfüzyonu yapılan hastaların transfüzyon sonrası değişim verilerin incelenmesi amacıyla prospektif olarak incelemektir. Bu çalıșma Sağlık Bilimleri Üniversitesi Bursa Yüksek İhtisas Eğitim ve Araștırma Hastanesi acil servisine başvuran hastaların yaş ve cinsiyetleri, şikayetleri, muayene bulguları, kan grupları, verilen kan ürünleri ve ünitelerinin dağılımı, transfüzyon öncesi ve sonrası hemoglobin $(\mathrm{Hb})$, hematokrit (Hct) değerleri incelenerek yapıldı. Çalışmaya 92 hasta alınmış olup hastaların \%56,5'u 65 yaş ve üzerindeydi. \%59,8'i kadındı. \%44,6 ile en fazla "halsizlik" şikayeti vardı. Muayenede hastaların \%17,4'inde melena \%14,1'inde hematokezya vardı. Hastaların \%40,2'si anemi ve \%35,9'u Gastrointestinal Sistem (GİS) kanaması tanısı almıștı. Hastalar en fazla \%45,7 ile A RH+ ve \%29,3 ile 0 RH + kan gruplarına sahipti. Hastaların \%94,6'sina eritrosit süspansiyonu (ES) ve \%5,4'üne ES+ taze donmuş plazma (TDP) transfüzyonu yapıldı. Hastaların \% 46,7 'sine iki ünite ES ve \%40,2'sine bir ünite ES verildi. Yaş gruplarının transfüzyon öncesi $\mathrm{Hb}$ değerleri arasında istatistiksel olarak önemli bir fark yokken $(\mathrm{p}=0,879)$, transfüzyon sonrası istatistiksel olarak önemli fark olduğu bulundu $(\mathrm{p}=0,003)$. ES transfüzyonu sonrası hastaların \%58,2'si beklenen $\mathrm{Hb}$ değerine ve \%50,0'si beklenen Hct değerlerine ulaşmıştı. Yaş, cinsiyet ve tanıya göre beklenen $\mathrm{Hb}$ ve Hct düzeylerine ulaşma durumları arasında istatistiksel olarak önemli fark yoktu $(p>0,05)$. Transfüzyon öncesi ve sonrası hastaların nabız, tansiyon ve ateş gibi vital bulgularında istatistiksel olarak fark yoktu $(p>0,05)$, ancak Hb, Hct, MCV ve MCH'de önemli artış vardı $(p<0,05)$. Çalışma sonunda acil serviste yapılan kan ve kan ürünü transfüzyonları incelendiğinde düşünülenin aksine travmaya bağlı acil transfüzyon değil de en fazla GíS kanama ve anemiye bağlı transfüzyon yapıldığı tespit edilmiştir.

Anahtar Kelimeler: Kan. Kan ürünü. Transfüzyon. Acil.

Characteristics of Blood Transfusion Patients in the Emergency Department

\begin{abstract}
The aim of this study was to prospectively examine the level of change in patients who received blood transfusion and blood products in the emergency department. This study was carried out in Health Sciences University Bursa Higher Specialization Training and Research Hospital Emergency Medicine Clinic between 15.01.2017 and 15.04.2017. Age, gender, complaints, examination findings, blood groups, distribution of blood products and units, and pre- and post-transfusion hemoglobin $(\mathrm{Hb})$ and hematocrit (Hct) levels were investigated. 92 patients were included in the study. $56.5 \%$ of the patients were 65 years or older. $59.8 \%$ were female. The most common complaint was weakness (44.6\%). During examination, it was found that $17.4 \%$ of the patients had melena and $14.1 \%$ had hematochezia. $40.2 \%$ of the patients were diagnosed as anemia and 35.9\% were diagnosed with gastrointestinal system bleeding. The most common blood group was A RH + (45.7\%) and $0 \mathrm{RH}+(29.3 \%) .94 .6 \%$ of the patients underwent erythrocyte suspension (ES) and 5.4\% had ES + fresh frozen plasma (TDP) transfusion. $46.7 \%$ of the patients received two units of ES and $40.2 \%$ received one unit of ES. While there was no statistically significant difference between the Hb values of the age groups before transfusion $(\mathrm{p}=0.879)$, there was a statistically significant difference after transfusion $(p=0.003)$. After ES transfusion, $58.2 \%$ of the patients had an expected $\mathrm{Hb}$ value and $50.0 \%$ had an expected Hct value. There was no statistically significant difference between $\mathrm{Hb}$ and Hct levels in terms of age, gender and diagnosis $(\mathrm{p}>0.05)$. There was no statistically significant difference in vital signs such as pulse, blood pressure and fever before and after transfusion ( $>>0.05$ ), but there was a significant increase in $\mathrm{Hb}, \mathrm{Hct}, \mathrm{MCV}$ and $\mathrm{MCH}(\mathrm{p}<0.05)$. In conclusion, when blood and blood product transfusions in the emergency department were examined, it was found that most common transfusions were GIS bleeding and anemia-related transfusions rather than trauma-induced emergency transfusions, which was contrary to the expectations.
\end{abstract}

Key Words: Blood. Blood product. Transfusion. Emergency.

Geliş Tarihi: 30 Mayıs 2019

Kabul Tarihi: 11 Ekim 2019

Dr. Yeşim IŞLER

Sağlık Bilimleri Üniversitesi,

Bursa Yüksek Ihtisas Eğitim ve Araştırma Hastanesi,

Acil Tıp Kliniği, Bursa.

Tel.:0505 2359153

E-posta:yesimisler@gmail.com
Kan, her biri ayrı fonksiyonları olan spesifik yapılardan oluşmuş canlı bir dokudur. Kan transfüzyonu ise bir doku hatta organ naklidir ${ }^{1}$. 20. yüzyılın başında kan grubu antijenlerinin, tipleme yöntemlerinin ve verici-alıcı karşılaştırma testlerinin keşfi ile tıptaki uygulama alanına girmiştir ${ }^{2}$. Daha sonra uygun antikoagülanların, kanın fraksinasyonuna olanak sağlayan 
biyolojik olarak uygun plastik torba sisteminin ve hastalık geçişini önlemek için birçok mikrobiyolojik testin keşfiyle "kan komponenti" tedavisi modern kavramları aşamalı olarak gelişmiştir. Kan ürünleri kandan hazırlanan tüm terapötik materyaller yani hem kan komponentleri hem de plazma fraksinasyon ürünlerini kapsarken, kan komponentleri ile eritrosit, lökosit, trombosit konsantreleri, plazma ve kriyopresipitat anlaşılmaktadır.

Başlıca transfüzyon endikasyonları arasında kan volümünü yerine koymak, eksik kan komponentlerinin yerine konması (eritrosit, trombosit, lökosit, pıhtılaşma faktörleri, plazma proteinleri), kan değişimi ve vücut dışı dolaşım uygulanması, dokulara oksijen transportunu sağlamak, kanama ve koagülasyon bozukluklarını ve immunolojik yetersizlikleri düzeltmek sayılabilir. Transfüzyon kararı alırken hastada gerçekten transfüzyon ihtiyacı olup olmadığı, eğer bu ihtiyaç var ise gerek duyulan komponentin hangisi olduğu, hastaya yaklaşık kaç ünite transfüzyon yapılması gerektiği ve verilecek kan veya kan ürününün hastaya yararı/zararının ne olduğu mutlaka gözden geçirilmelidir ${ }^{1}$.

Hastanemizde kan merkezinden acil servise transfüzyon amacıyla alınan kan ve kan ürünlerinin miktarı, grubu, transfüzyonların hangi hastalara yapıldığı, hastanın tanısı ve transfüzyonların Hb ve Hct değerlerine literatürde belirtildiği ölçüde yükselme sağlayıp sağlamadığının, kan $\mathrm{Hb}$ ve Hct değerlerini ne kadar yükselttiğinin araştırılması amacıyla bu çalışma planlanmıştır.

\section{Gereç ve Yöntem}

Bu çalışma, hastanemiz 2017/01-10 nolu etik kurul izni ile gerçekleştirilmiştir. Çalışmada 15.01.201715.04.2017 tarihleri arasında acil serviste kan transfüzyonu yapılan hastalar incelenerek transfüzyon yapılan hastalarda kan $\mathrm{Hb}$ ve Hct değerlerindeki değişim verileri değerlendirilmiştir. Transfüzyon yapılan hastalar için kullanılacak kan veya kan ürünleri hastanemiz kan merkezinde hazırlatılmıştır.

Hastaların yaş ve cinsiyetleri, şikayetleri, muayene bulguları, kan grupları, verilen kan ürünleri ve ünitelerinin dağılımı değerlendirildi. Yaş grupları ve cinsiyete göre eritrosit süspansiyonu (ES) transfüzyonu öncesi ve sonrası Hb, Hct değerlerinin dağılımı ele alındı. Çalışmaya 18 yaş üstü, semptomatik anemi bulguları olan hastalar dahil edilmiştir. Sadece TDP alan hastalar çalışma dışı bırakılmıştır. Ayrıca yaş, cinsiyet, transfüzyon öncesi ve sonrası $\mathrm{Hb}$ ve Hct değerleri arasındaki korelasyon transfüzyon öncesi ve sonrası hastaların vital bulguları ile kan değerlerinin karşılaştırılması prospektif olarak incelendi. Toplam 100 hastaya transfüzyon yapıldı. 8 hasta sadece TDP aldığı için çalışma dışı bırakıldı.
Çalışmada istenen veriler için bir form hazırlandı ve bu forma; alıcının adı, soyadı, yaşı, cinsiyeti, barkod numarası, şikayeti, muayene bulguları, tanısı, kan grubu, verilen kan ürünü, transfüzyon endikasyonu ve hangi kan ürününü hangi miktarda aldığı, transfüzyon öncesi ve sonrası vital bulgular (kan basınc1, nabız, ateş) ile $\mathrm{Hb}$ ve Hct değerleri kaydedildi. Acil servisten tranfüzyon için kan ve kan ürünü isteminde bulunulduğunda once alıcının kan grubu belirlenip, daha sonra tam kan (TK) ve ES için çapraz karşılaştırma yapılarak uygunluk tespiti yapıldı. Transfüzyon öncesi ve sonrası değerler sorumlu hekim tarafından çalışma formuna kaydedildi.

\section{İstatistiksel Analiz}

Veriler SPSS 21.0 bilgisayar istatistik programına girilerek analiz edildi. Veriler sayı, yüzde, ortalama ve standart sapma (SS) olarak sunuldu. Nümerik verilerin normallik dağılımı Kolmogorov-Smirnov testi ile incelendi. Yaş gruplarının tedavi öncesi ve sonrası gruplar arası $\mathrm{Hb}$ ve Hct değerleri tek yönlü ANOVA ile (ikili grup karşılaştırmaları post hoc LSD ile) karşılaştırırken, grup içi karşılaştırmaları bağımlı gruplarda t testi ile yapıldı. Cinsiyet grubunun tedavi öncesi ve sonrası gruplar arası $\mathrm{Hb}$ ve Hct değerleri bağımsız gruplarda t testi ile, grup içi karşılaştırmaları ise bağımlı gruplarda t testi ile yapıldı. Yaş, cinsiyet ve tanıya göre beklenen $\mathrm{Hb}$ ve Hct değerine ulaşma durumunun analizinde Ki-Kare testi (gerektiğinde Fisherexact test) kullanıldı. Transfüzyon öncesi ve sonrası $\mathrm{Hb}$ ve Hct değerlerinin korelasyonu Pearson korelasyon analizi ile yapıldı. Transfüzyon öncesi ve sonrası hastaların vital bulguları ile kan değerlerinin karşılaştırılması bağımlı gruplarda $t$ testi ile yapıldı. İstatistiksel önemlilik düzeyi $p<0,05$ alındı.

\section{Bulgular}

Toplam 92 hastanın \%56,5'u (n=52) 65 yaş ve üzerindeydi. \%59,8'i $(n=55)$ kadindı. \%44,6 ile en fazla "halsizlik" şikayeti vardı. Muayenede hastalarin \%17,4'inde $(n=16)$ melena \%14,1'inde $(n=13)$ hematokezya vardı. Hastaların \%40,2'si $(n=37)$ anemi ve \%35,9'u (n=33) GİS kanaması tanısı almıştı. Araştırmaya alınan hastaların temel özellikleri Tablo I'de verilmiştir.

Hastalar en fazla \%45,7 ( $\mathrm{n}=42)$ ile A RH+ ve \%29,3 $(\mathrm{n}=27)$ ile $0 \mathrm{RH}+$ kan gruplarına sahipti. Hastaların \%94,6'sına (n=87) ES ve \%5,4'üne (n=5) ES+TDP transfüzyonu yapıldı. Hastaların \%46,7'sine $(n=43)$ iki ünite ES ve \%40,2'sine (n=37) bir ünite ES verilmişti. Hastaların kan grupları, verilen kan ürünleri ve ünitelerinin dağılımı Tablo II'de verilmiştir. Yaş grupları ve cinsiyete göre ES transfüzyonu yapılan hastaların transfüzyon öncesi ve sonrası $\mathrm{Hb}$ değerlerinin karş1laştırılması Tablo III’te verilmiştir. Yaş gruplarının 


\section{Acilde Kan Transfüzyonu}

transfüzyon öncesi $\mathrm{Hb}$ değerleri arasında istatistiksel olarak önemli bir fark yokken $(F=0,13 ; p=0,879)$, transfüzyon sonrası istatistiksel olarak önemli fark olduğu bulundu $(F=6,14, p=0,003)$. Yapilan posthoc LSD analizinde 65 yaş ve üstü gruptaki hastaların $\mathrm{Hb}$ değerinin $(8,81 \pm 1,79 \mathrm{~g} / \mathrm{dl}) \quad 16-45$ yaş grubu $(7,52 \pm 1,17 \mathrm{~g} / \mathrm{dl})$ ve $46-64$ yaş grubundan $(7,79 \pm 1,26 \mathrm{~g} / \mathrm{dl})$ daha yüksek olduğu bulundu $(p<0,05)$ Bütün yaş gruplarında transfüzyon sonrası $\mathrm{Hb}$ değerlerinde transfüzyon öncesine göre istatistiksel olarak önemli artış vardı $(p<0,01)$. Benzer olarak, hem kadınlarda hem de erkeklerde transfüzyon sonrası Hb değerlerinde transfüzyon öncesine göre istatistiksel olarak önemli artış vardı $(p<0,001)$.

Tablo I. Hastaların temel özellikleri.

\begin{tabular}{llcc}
\hline & & $\mathrm{n}$ & $\%$ \\
\hline Yaş (yıl) & $16-45$ & 19 & 20,7 \\
& $46-64$ & 21 & 22,8 \\
& 65 ve üstü & 52 & 56,5 \\
\hline Cinsiyet & Kadın & 55 & 59,8 \\
& Erkek & 37 & 40,2 \\
\hline Şikayet & Halsizlik & 41 & 44,6 \\
& Makatta kanama & 29 & 31,4 \\
& Diğer* & 22 & 24,0 \\
\hline \multirow{4}{*}{ Melena } & Yok & 76 & 82,6 \\
& Var & 16 & 17,4 \\
\hline \multirow{2}{*}{ Hematokezya } & Yok & 79 & 85,9 \\
& Var & 13 & 14,1 \\
\hline Tanı & Gis kanama & 33 & 35,9 \\
& Anemi & 37 & 40,2 \\
& Hemoroid & 5 & 5,4 \\
& Diğer* & 17 & 18,5 \\
\hline
\end{tabular}

* Menoraji, Metroraji, Epistaksis,

** Malignite, Myoma uteri,

Tablo II. Hastaların kan grupları, verilen kan ürünleri ve ünitelerinin dağılımı.

\begin{tabular}{llcc}
\hline & & $\mathrm{n}$ & $\%$ \\
\hline Kan grubu & $\mathrm{A} \mathrm{RH}+$ & 42 & 45,7 \\
& $\mathrm{~A} \mathrm{RH}-$ & 3 & 3,3 \\
& $\mathrm{~B} \mathrm{RH}+$ & 11 & 12,0 \\
& $\mathrm{~B} \mathrm{RH}-$ & 2 & 2,2 \\
& O RH + & 27 & 29,3 \\
& $0 \mathrm{RH}-$ & 3 & 3,3 \\
& $\mathrm{AB} \mathrm{RH}+$ & 2 & 2,2 \\
& AB RH- & 2 & 2,2 \\
\hline Kan ürünü & Eritrosit süspansiyonu & 87 & 94,6 \\
& Eritrosit+TDP & 5 & 5,4 \\
\hline Eritrosit & 1 Ünite ES & 37 & 40,2 \\
& 2 Ünite ES & 43 & 46,7 \\
& 3 Ünite & 10 & 10,9 \\
& 4 Ünite ES & 2 & 2,2 \\
\hline
\end{tabular}

Tablo III. Yaş grupları ve cinsiyete göre ES transfüzyonu öncesi ve sonrası $\mathrm{Hb}$ değerlerinin dağlımı.

\begin{tabular}{|c|c|c|c|c|}
\hline & TÖ Hb (g/dl) & $\mathrm{TS} \mathrm{Hb} / \mathrm{g} / \mathrm{dl}$ & & \\
\hline & Ort. $\pm S S$ & Ort. $\pm S S$ & $\mathrm{t}$ & $p$ \\
\hline \multicolumn{5}{|l|}{ Yaş grupları } \\
\hline $16-45$ & $6,31 \pm 1,09$ & $7,52 \pm 1,17^{a}$ & 6,56 & 0,000 \\
\hline $46-64$ & $6,56 \pm 1,76$ & $7,79 \pm 1,26^{a}$ & 3,90 & 0,001 \\
\hline 65 yaş ve üstü & $6,49 \pm 1,78$ & $8,81 \pm 1,79 b$ & 9,68 & 0,000 \\
\hline $\mathrm{F}$ & 0,13 & 6,14 & & \\
\hline$p$ & 0,879 & 0,003 & & \\
\hline \multicolumn{5}{|l|}{ Cinsiyet } \\
\hline Kadın & $6,25 \pm 1,60$ & $8,28 \pm 1,73$ & 9,15 & 0,000 \\
\hline Erkek & $6,79 \pm 1,67$ & $8,34 \pm 1,56$ & 6,34 & 0,000 \\
\hline$t$ & 1,56 & 0,17 & & \\
\hline$p$ & 0,122 & 0,862 & & \\
\hline
\end{tabular}

a,b. Farklı harfler Post Hoc LSD yaş grup karşılaştırmalarinda

$\mathrm{p}<0.05$ olan grupları göstermektedir.

TÖ: Transfüzyon öncesi, TS: Transfüzyon sonrası

Ort. Ortalama, SS. Standart sapma

Yaş grupları ve cinsiyete göre ES transfüzyonu yap1lan hastaların transfüzyon öncesi ve sonrası Hct değerlerinin karşılaştırılması Tablo IV’te verilmiştir. Yaş gruplarının transfüzyon öncesi Hct değerleri arasında istatistiksel olarak önemli bir fark yokken $(F=0,00$; $\mathrm{p}=0,998)$, transfüzyon sonrası istatistiksel olarak önemli fark olduğu bulundu $(\mathrm{F}=3,75, \mathrm{p}=0,027)$. Yap1lan posthoc LSD analizinde 65 yaş ve üstü gruptaki hastaların Hct değerinin $(27,19 \pm 5,50), 46-64$ yaş grubundan $(24,15 \pm 3,37)$ yüksek olduğu bulundu $(p<0,05)$. Bütün yaş gruplarında ve cinsiyette transfüzyon sonras1 Hct değerlerinde transfüzyon öncesine göre istatistiksel olarak önemli artış vardı $(p<0,001)$.

Tablo IV. Yaş grupları ve cinsiyete göre ES transfüzyonu öncesi ve sonrası Hct değerlerinin dağılımı.

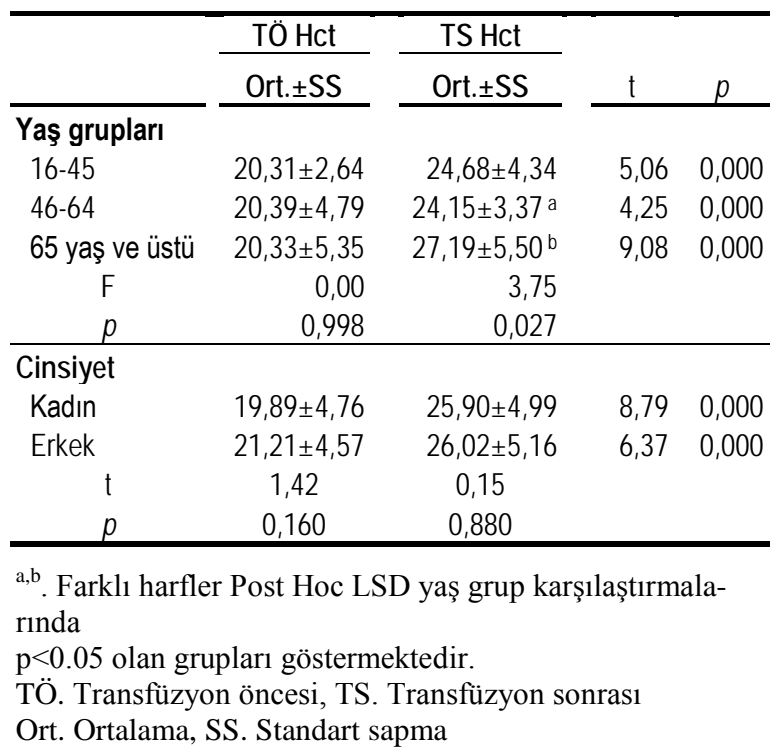


ES transfüzyonu sonrası hastaların \%58,2'si ( $\mathrm{n}=53)$ beklenen $\mathrm{Hb}$ değerine ve \%50,0'si $(\mathrm{n}=45)$ beklenen Hct değerlerine ulaşmıştı. Yaş, cinsiyet ve tanıya göre beklenen $\mathrm{Hb}$ ve Hct düzeylerine ulaşma durumları arasında istatistiksel olarak önemli fark yoktu $(p>0,05)$ (Tablo V).

Tablo V. Yaş, cinsiyet ve tanıya göre beklenen $\mathrm{Hb}$ ve Hct değerlerine ulaşma durumunun dağ $11_{1-}$ mi.

\begin{tabular}{|c|c|c|c|c|c|c|c|c|}
\hline & \multicolumn{3}{|c|}{$\begin{array}{c}\text { Beklenen } \mathrm{Hb} \\
\text { değerine ulaşma }\end{array}$} & \multicolumn{4}{|c|}{$\begin{array}{c}\text { Beklenen Hct } \\
\text { değerine ulaşma }\end{array}$} \\
\hline & & Hayır & \multicolumn{2}{|c|}{ Evet } & \multicolumn{2}{|c|}{ Hayır } & \multicolumn{2}{|c|}{ Evet } \\
\hline & & $\mathrm{n} \quad \%$ & $n$ & $\%$ & $\mathrm{n}$ & $\%$ & $\mathrm{n}$ & $\%$ \\
\hline Yaş & $16-45$ & 1157,9 & 8 & 42,1 & 13 & 68,4 & 6 & 31,6 \\
\hline \multirow[t]{3}{*}{ (yıl) } & $46-64$ & 1047,6 & 11 & 52,4 & 12 & 57,1 & 9 & 42,9 \\
\hline & 65 ve üstü & 1733,3 & 34 & 66,7 & 20 & 40,0 & 30 & 60,0 \\
\hline & & \multicolumn{3}{|c|}{$x^{2}=3,82 ; p=0,148$} & \multicolumn{4}{|c|}{$x^{2}=5,01 ; p=0,082$} \\
\hline Cin- & Kadın & 2240,7 & 32 & 59,3 & 28 & 51,9 & 26 & 48,1 \\
\hline \multirow[t]{2}{*}{ siyet } & Erkek & 1643,2 & 21 & 56,8 & 17 & 47,2 & 19 & 52,8 \\
\hline & & \multicolumn{3}{|c|}{$X^{2}=0,06 ; p=0,812$} & \multicolumn{4}{|c|}{$x^{2}=0.19 ; p=0.667$} \\
\hline \multirow[t]{5}{*}{ Tanı } & $\begin{array}{l}\text { GiS } \\
\text { Kanama }\end{array}$ & 1340,6 & 19 & 59,4 & 16 & 50,0 & 16 & 50,0 \\
\hline & Anemi & 1643,2 & 21 & 56,8 & 20 & 55,6 & 16 & 44,4 \\
\hline & Hemoroid & 240,0 & 3 & 60,0 & 1 & 20,0 & 4 & 80,0 \\
\hline & Diğer & $7 \quad 41,2$ & 10 & 58,8 & 8 & 47,1 & 9 & 52,9 \\
\hline & & \multicolumn{3}{|c|}{$\begin{array}{l}\text { Fisher'sExact Test; } \\
\qquad p=1,00\end{array}$} & \multicolumn{4}{|c|}{$\begin{array}{l}\text { Fisher'sExactTest ; } \\
\qquad p=0,585\end{array}$} \\
\hline
\end{tabular}

Transfüzyon öncesi $\mathrm{Hb}$ ve Hct arasında pozitif yönde çok güçlü ve istatistiksel olarak önemli korelasyon vard1 $(\mathrm{r}=0,961, p<0,001)$ (Şekil 1). Aynı şekilde transfüzyon sonrası $\mathrm{Hb}$ ve Hct arasında pozitif yönde çok güçlü ve istatistiksel olarak önemli korelasyon vard1 $(\mathrm{r}=0,816, p<0,001)$ (Şekil 2).

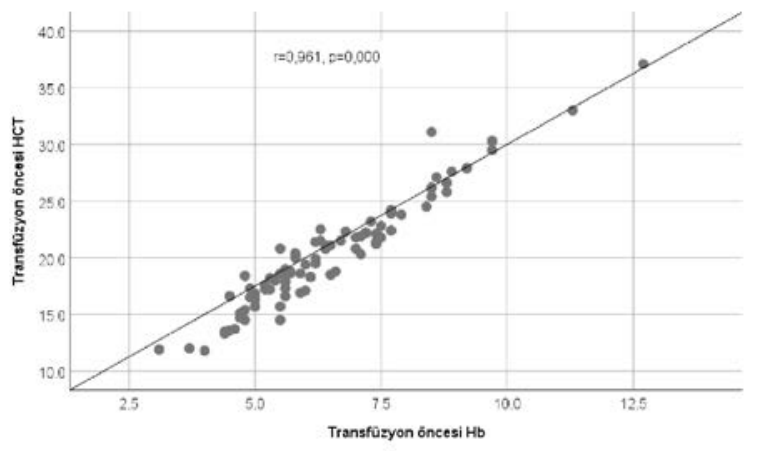

Şekil 1.

Transfüzyon öncesi Hb ve Hct değerleri arasındaki korelasyon.

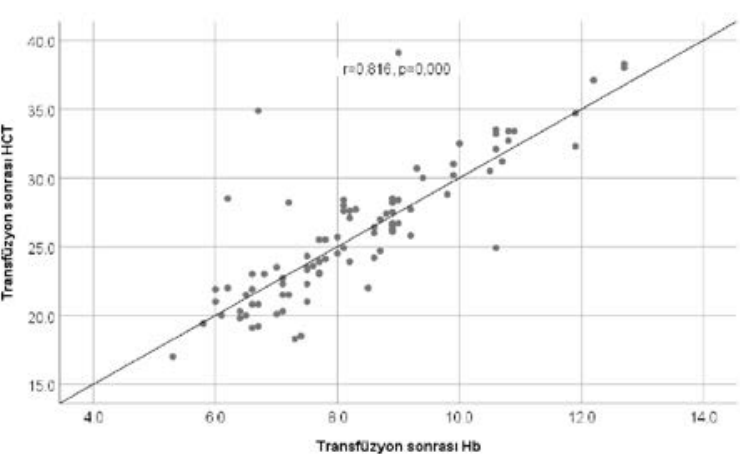

Şekil 2 .

Transfüzyon sonrası Hb ve Hct diğerleri arasındaki korelasyon.

Transfüzyon öncesi ve sonrası hastaların nabız, tansiyon ve ateş gibi vital bulgularında istatistiksel olarak fark yoktu $(p>0,05)$, ancak Hb, Hct, MCV ve MCH'de önemli artış vardı $(p<0,05)$.

Transfüzyon öncesi $(0,32 \pm 0,02)$ ve sonras1 $(0,32 \pm 0,03) \mathrm{Hb} / \mathrm{Hct}$ oranlarında istatistiksel olarak fark yoktu $(\mathrm{t}=1,09, p=0,28)$.

\section{Tartışma}

Kan her biri ayrı fonksiyonları olan spesifik yapılardan oluşmuş bir canlı dokudur. Kan transfüzyonu ise bir doku hatta organ transplantasyonudur ${ }^{3}$.

Biz çalışmamızda öncelikle acil servise hangi yaş grubundaki hastaların gelip bu hastaların hangi şikayetlerle ne tanılar aldığını belirlemek istedik. Bu tanılara uygun olarak da kaç ünite eritrosit transfüzyonu verdiğimizi ve transfüzyon öncesinde ve sonrasında $\mathrm{Hb}$ ve Hct değerleri, vital değerlerde değişiklik olup olmadığını belirlemek istedik.

Akut GİS kanama sıklığı yaş, cinsiyet, kullanılan ilaçlar ve kan gruplarına göre değişmektedir. Rodriguez ve arkadaşlarının yaptıkları bir çalışmada kanama sıklığının 60-80 yaş arasında ve özellikle kadınlarda \%66 oranına ulaştığı tespit edilmiştir ${ }^{4}$. Ünsal B ve arkadaşlarının çalışmasında, 60 yaş ve üzerinin, akut GİS kanamanın risk faktörü olarak kabul edilmiştir $^{5}$.Vilanueva ve arkadaşlarının yaptığı diğer bir çalışmada ise altı yıl boyunca izledikleri hastalarda cinsiyet ve yaş bakımından farka rastlanmamışıิır ${ }^{6}$. Dursun $M$ ve arkadaşlarının yapmış olduğu 1242 hastalık bir çalışmada erkek oranı \%76.2 ve yaş ortalaması 47 bulunmuştur ${ }^{7}$. Bizim çalışmamızda ise yaş ortalaması literatür ile uyumlu iken kadın oranı fazla çıkmıştır. Ancak literatürde yapılan çalışmalarda cinsiyet oranları farklılıklar göstermektedir.

Bu tür hastalarda aneminin hipoksiye bağlı, acil tedavi gerektiren semptomlarının ortaya çıkması durumunda eritrosit süspansiyonu verilmelidir. $\mathrm{Bu}$ semptomlar yorgunluk, halsizlik, solukluk, kısa ve sik soluma, 


\section{Acilde Kan Transfüzyonu}

taşikardi, senkop, serebral hipoksi belirtileri, angina pektoris ve kalp yetmezliğidir.

Kronik anemilerde hastalar; 7-8 g/dl Hb değerini tolere edebilir. Solunum yetmezliği, koroner arter hastal1$\breve{g} 1$, serebrovasküler hastalıklar ve orta-ağır derecede kalp yetmezliği gibi bazı durumlarda hemoglobin değeri yüksek olsa da eritrosit transfüzyonuna gerek duyulabilir ${ }^{3}$.

Eritrosit süspansiyonları sadece oksijen taşıma kapasitesinde ve eritrosit kitlesinde artışa gereksinimi olan normovolemik hastalarda anemi tedavisi için endikedir. Böbrek yetmezliği veya malignite nedeniyle oluşan kronik anemili hastalar bu grubu oluşturur. Her hastanın transfüzyon gereksinimi daha önceden belirlenmiş hemoglobin ve hematokrit değerine göre değil, hastanın klinik durumuna göre belirlenmelidir. ES, kalp yetmezliği olan anemili hastaların aşırı volüm artışını tolere edememeleri nedeni ile tam kandan daha avantajlıdır ${ }^{8}$.

Paksoy ve arkadaşlarının yaptığı 772 olgudan oluşan çalışmada hastaların \%32'sinde melena, \%21'inde hematemez ve \%47'sinde hematemez ve melena tespit edilmiştir ${ }^{9}$. Diğer iki farklı çalışmada ise \%32.1\%60.3 sadece melena, \%14.5- \%17.9 sadece hematemez, \%25- \%50 hematemez ve melena tespit edilmiş$\operatorname{tir}^{10,11}$. Bizim çalışmamızda literatür ile uyumlu çıkmiştır.

$\mathrm{ABO}$ ve Rh kan grubu profili; etnik ve ırka bağlı olarak farklılıklar göstermektedir. Amerika Birleşik Devletlerinde yapılan geniş katılımlı bir çalışmada A,O,B ve $\mathrm{AB}$ kan grubu dağılımı sirasıyla \% 37.1, \%46.7, \%12.2, \%4.1 olarak bulunmuş ve $\mathrm{Rh}$ pozitiflik oranı \% 85.4 olarak tespit edilmiştir ${ }^{12}$. Ülkemiz genelinde yapılan çalışmalarda $A, O, B$ ve $A B$ kan grubu dağılımı sirasıyla \%42.84, \%32.67, \%16.46, \%8.03 olarak tespit edilmiştir. Ülkemiz genelinde $\mathrm{Rh}$ pozitiflik oranı \% 88.54 olarak saptanmıștır ${ }^{13}$.

Okutur ve arkadaşlarının yaptığı çalışmada ise 84 hasta ORh+ (\%36.5) ve 76 hasta ARh+ (\%33.0) ile ilk iki grubu oluşturmuştur ${ }^{14}$.

Bizim çalışmamızda da benzer olarak her iki grup en çok karşılaşılan kan grupları olmuştur. Hastalar en fazla \%45,7 ile A RH+ ve \%29,3 ile $0 \mathrm{RH}+$ kan gruplarına sahipti.

Kullanılan kan ürünlerinin türü ve miktarı incelendiğinde Rao ve ark. çalışmasında yapılan transfüzyonların \%53'ünün ES \%16'sının Trombosit Süspansiyonu (TS) ve \%22'sinin de TDP olduğu görülmüştür ${ }^{15}$. Ülkemizde Malatya bölgesinde yapılan bir çalışmada \%19.3 oranında TK, \%33.9 oranında ES, \%34.9 oranında TDP ve \%11.9 oranında TS kullanılmıştır ${ }^{16}$.

Bizim çalışmamızda hastaların \%94,6'sına ES ve $\% 5,4$ 'üne ES+TDP transfüzyonu yapıldı. Hastaların \%46,7'sine iki ünite ES ve \%40,2'sine ise bir ünite ES verildi.
Bu çalışmanın bazı kısıtlılıkları mevcuttur. Öncelikle transfüzyon yapılan kronik anemili hastaların etyolojisi acil serviste ayrıntılı olarak incelenemedi. Ayrıca ek hastalıklarının olup olmadığı ve anemi üzerine olan etkilerine bakılamadı.

\section{Sonuç}

Yapılan bu çalışmada kan ve kan ürünü transfüzyonları incelendiğinde düşünülenin aksine travmaya bağlı acil transfüzyon değil de en fazla GİS kanama ve anemiye bağlı transfüzyon yapıldığı tespit edildi. Ayrıca transfüzyon sonrası takiplerde de hastaların vital bulgularında ve kan değerlerinde anlamlı düzeyde yükselme olduğu saptand. Anemiye ve GİS kanamasına neden olan asıl faktörün tedavisi veya nedenin ortadan kaldırılması hem hastalar hem de acil servislerin yükünü çok azaltacağından bu konuda çalışmalar yapılması uygun olacaktır.

\section{Kaynaklar}

1. Vengelen-Tyler V. Non infectious Complications of Blood Transfusion. In Technical Manual. 12th ed. Bethesda, MD: American Association of Blood Banks. 1996; 558-9.

2. Hillman RS, Kenneth AA: Blood Component Therapy. In: Hematology in Clinical Practice . 3rd ed. 2002, 407-416.

3. Mahmut Bayık Kanın klinik kullanımıyla ilgili politika rehber ve komiteler Ulusal kan merkezleri ve Transfüzyon tıbbı kursu IX Kurs Kitabı. 2006; S 101-125

4. Rodriguez-Hernandez H, Jacobo-Karam JS, Jaquez Quintana JO, AvilaRomero HG, Galvan-Roman L, Lara-Miranda SC, et al. Gastropathy caused by non steridal anti inflammatory agents and its association with Helicobacter pylori. RevInvestClin 2003; 55: 254-9.

5. Ünsal B, Altınay ZA, Kara B. 1987-1991 yıllarında kliniğimizde yatan üst gastrointestinal sistem kanamaları ve bunların ilaca bağlı olanların değerlendirilmesi. Gastroentereloji 1993; 4: 4602 .

6. Villanueva Palacios J, Lopez de Guimmanes D, Avila Polo F. Upper digestive tract hemorrhage in the Peruvian Andes: report of 115 cases observed in Huaraz. RevGastroenterol Peru 1996; 16: 99-104.

7. Dursun M, Yılmaz S, Yükselen V, Canoruç F, Tuzcu A. Analysis of 1242 cases with upper gastrointestinal system bleeding in Southeastern Turkey: a different etiyolojik spectrum. Hepatogastroenterology 2005; 52: 1456-81

8. Lane TA (ed.). Blood Components In: Blood Transfusion Therapy: A Physician Handbook. 5th ed. Bethesda, MD: American Association of Blood Banks, 1996: 3-33.

9. Paksoy M, Yavuz N. Akut üst Gastrointestinal Sistem kanamasinda mortaliteyi etkileyen risk faktörleri. T KlinSurgery 2000; 5: 53-8.

10. Elmas K. Üst gastrointestinal sistem kanamalı hastaların değerlendirilmesi. Akademik Gastroenteroloji 2008; 7: 171-3.

11. Coban E, Süleymanlar İ, Ertuğrul C. Gastrointestinal sistem kanamalar: 177 olgunun değerlendirilmesi. Türk J Gastroenterol 1997; 8 Suppll:35.

12. Garratty G, Glynn SA, McEntire R. ABO andRh(D) phenotype frequencies of differentracial/ethnic groups in the United States. Transfusion44:703-706, 2004. 
Y. İşler, ark.

13. Yakıncı C, Durmaz Y, Şahin S ve ark. Malatya Yöresinde ABO ve Rh Kan Gruplarının Dağılımı. Turgut Özal Tıp Merkezi Derg2:277-279, 1995

14. Okutur S, Alkım C, Bes C, Gürbüz D, Kınık Ö, Gültürk E, ve ark. Akut üst gastrointestinal sistem kanamaları: 230 olgunun analizi. Akademik Gastroenteroloji Derg 2007; 6: 30-6

15. Rao MP, Boralessa H, Morgan C, Soni N, Goldhill DR, Brett SJ, et al. Blood componentuse in critically ill patients. Anaesthesia. 2002; 57: 527-9. [CrossRef]
16. Kaya E, Kuku İ, Harputluoğlu H, Özkan H.İ, Demircan M, Aydoğdu İ. İnönü Üniversitesi Tıp Fakültesi Turgut Özal Tıp Merkezi Kan Bankası. Bankamızdaki Kan Ürünleri Ve Kullanım Oranlar. I. Ulusal Kan Merkezleri ve Transfüzyon Tıbbı Kongresi. Kongre/KursKitab1, Nurol Matbaacılık, Poster29,2000, Kapadokya 